\title{
Clinical Implication of Mid-Range Dynamic Instability in Lumbar Degenerative Spondylolisthesis
}

\author{
Chang-Yk Lee ${ }^{1}$, Byeong-Mun Park², Tae-Woo Kim², Seung-Hwan Lee ${ }^{2}$ \\ ${ }^{1}$ Department of Orthopedic Surgery, Lee Chun-Tek Orthopedic Specialty Hospital, Suwon, Korea \\ ${ }^{2}$ Department of Orthopaedic Surgery, Gwangmyeong Sungae Hospital, Gwangmyeong, Korea
}

\section{Study Design: Retrospective evaluation.}

Purpose: To determine the prevalence of mid-range dynamic instability in patients with degenerative spondylolisthesis (DS) and to evaluate the clinical implication of mid-range instability (MI).

Overview of Literature: Instability is identified by measuring vertebral body anterior-posterior translation on static end-range flexion and extension lateral radiographs. Mid-range kinematics could evince occult dynamic instability in which motion is not appreciated at the terminal-range of motion.

Methods: In this study, 30 patients with DS with checked standing dynamic radiographs of the lumbar spine in Gwangmyeong Sungae Orthopedic Clinic were recruited. Standing lateral radiographs were evaluated in extension, $45^{\circ}$ of flexion (mid-range) and $90^{\circ}$ of flexion (terminal-range) of the lumbar spine. Instability was defined as sagittal translation greater than $3 \mathrm{~mm}$ from the extension position. Patients were divided into three groups: a control group, an MI group, and a terminal-range instability (TI) group. Radiographic outcome (stenosis grade) and clinical outcome were compared between the three groups.

Results: The average sagittal translation of the lumbar spine was $5.2 \mathrm{~mm}$ in extension, $6.6 \mathrm{~mm}$ in mid-range, and $7.2 \mathrm{~mm}$ in endrange. MI was observed in eight patients (26.2\%) and TI was seen in 12 patients $(40 \%)$. Of eight patients with $\mathrm{MI}$, three patients did not have instability at terminal-range (occult patients) and five patients had instability at terminal-range (typical patients). Body weight and body mass index (BMI) was significantly higher in the MI group as compared to the control group. BMI was positively correlated with slippage to mid-range. There was no significant difference in stenosis grade, Visual Analog Scale, and Oswestry Disability Index. In the TI group, there was no significant difference in radiographic clinical parameters as compared to the control group. Conclusions: MI was demonstrated in 25\% of DS patients. Mid-range motion was increased with BMI. Mid-range lateral radiography can reveal occult instability in patients with DS, particularly in obese patients.

Keywords: Spondylolisthesis; Mid-range instability; Lumbar vertebrae

\section{Introduction}

Degenerative spondylolisthesis (DS) represents a patho- logic increase in sagittal vertebral motion secondary to loss of the anatomic restraint of the intervertebral disc and facet joints. DS in the setting of symptomatic lumbar

Received Feb 27, 2020; Revised May 21, 2020; Accepted Jun 20, 2020

Corresponding author: Seung-Hwan Lee

Department of Orthopedic Surgery, Gwangmyeong Sungae Hospital, 36 Digital-ro, Gwangmyeong 14241, Korea

Tel: +82-2-2680-7699, Fax: +82-2-2680-7755, E-mail: java5885@gmail.com 
spinal stenosis is commonly treated with spinal fusion in addition to decompression with laminectomy and is accepted by many as the surgical standard of care [1-4]. However, some studies have shown acceptable results with decompression alone.

A discussion of lumbar stability is critical to the understanding of DS and its contemporary management. Spondylolisthesis in this setting represents a pathologic increase in motion secondary to loss of the anatomic restraint of the intervertebral disc and facet joints. However, a simple binary classification of "stable" or "unstable" is inadequate to fully characterize DS and may be insufficient to guide clinical decision making. Specifically, DS can be further defined by the presence or absence of dynamic instability. Dynamic instability may be defined as segmental anterior-posterior (AP) translation occurring actively with flexion or extension of the lumbar spine. The presence of a dynamic phenotype has been shown to be an important risk factor for predicting failure of decompression and laminectomy without fusion [5].

Instability is identified by measuring the anterior-posterior translation on static end-range flexion and extension lateral radiographs and defined as a change of greater than $3 \mathrm{~mm}$ [6-14]. Mid-range kinematics could evince occult dynamic instability in which motion is not appreciated at the terminal-range of motion. We evaluated the prevalence of mid-range instability (MI) and analyzed the clinical implication of MI.

\section{Materials and Methods}

In this study, 30 patients with DS who had checked standing dynamic radiographs and magnetic resonance imaging (MRI) of the lumbar spine in Gwangmyeong Sungae orthopedic clinic were recruited (Table 1). This study received an exemption by the Institutional Review Board of Gwangmyeong Sungae Hospital (KIRB-2020-N-002), and informed consent was obtained from all individual participants included in the study.

\section{Radiographical assessment}

Standing lateral radiographs were evaluated in extension, $45^{\circ}$ of flexion (mid-range) and $90^{\circ}$ of flexion (terminalrange) of the lumbar spine $[9,15]$. Since it is impossible to accurately measure the angle of the mid-range, the midrange was decided to be between $30^{\circ}$ and $60^{\circ}$. I tried to
Table 1. Demographic data

\begin{tabular}{lc} 
Characteristic & Value \\
\hline No. of patients & 30 \\
\hline Male & 12 \\
\hline Female & 18 \\
\hline Age $(\mathrm{yr})$ & $68.43 \pm 8.62$ \\
\hline Weight $(\mathrm{kg})$ & $63.57 \pm 9.80$ \\
\hline Height $(\mathrm{cm})$ & $160.60 \pm 8.15$ \\
\hline Body mass index $\left(\mathrm{kg} / \mathrm{m}^{2}\right)$ & $24.60 \pm 3.09$ \\
\hline Leg VAS & $4.77 \pm 2.73$ \\
\hline Back VAS & $5.90 \pm 2.19$ \\
\hline Oswestry Disability Index & $23.50 \pm 9.47$ \\
\hline
\end{tabular}

Values are presented as number or mean \pm standard deviation. VAS, Visual Analog Scale.

make the lower leg straight from the pelvis to set the gross position close to $45^{\circ}$. The mid-range can best reflect the instability state with the hooking mechanism of the facet joint and the anterior longitudinal ligament and posterior longitudinal ligament of the disc not tense.

Clinical measurement of intervertebral AP translation was performed by two observers via the standard measuring approach [9]. Landmarks placed on the inferior-posterior endplate of the superior vertebra and the superiorposterior endplate of the inferior vertebra were used to calculate dynamic slippage. Instability was defined as slippage greater than $3 \mathrm{~mm}$ from the extension position [16]. Patients were divided into three groups: a control group, an MI group, and a terminal-range instability (TI) group.

\section{Outcome measurement}

Radiographic outcome (stenosis grade) and clinical outcome (Visual Analog Scale [VAS] and Oswestry Disability Index [ODI]) were compared between the three groups. All radiographic measurements, plain films, and MRIs were evaluated by an independent examiner who was not directly involved in the care or surgery of the patients. Two independent observers classified each case twice within a 1-week interval in order to measure intra and inter-observer differences. Kappa statistics were used to evaluate inter- and intra-observer reliability. Results of reliability tests (kappa statistics) were as follows: the intraobserver reliability for anterior slip varied between 0.86 and 0.90 . The inter-observer reliability ranged from 0.82 to 0.94 , respectively. 


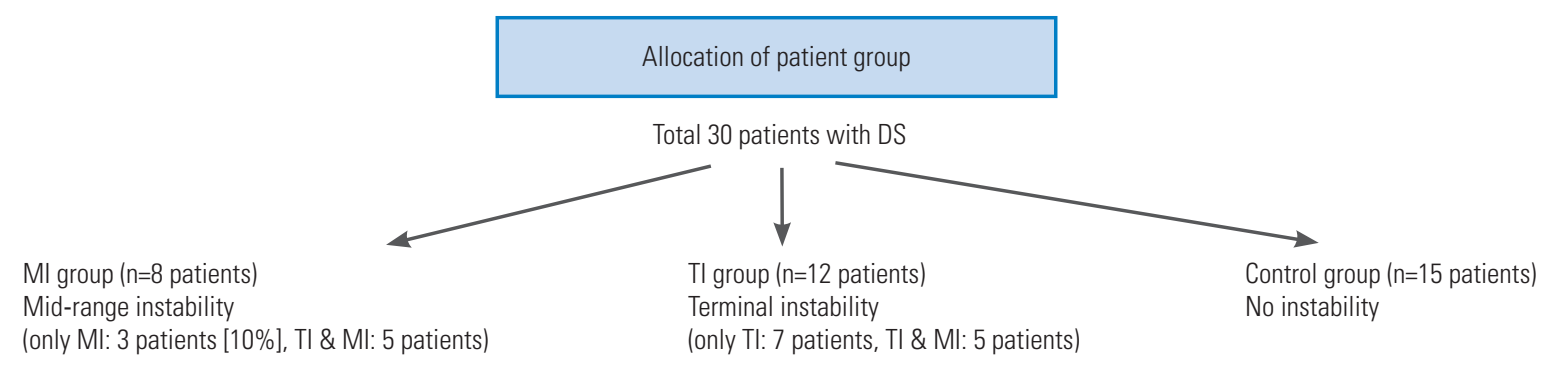

Fig. 1. Flow diagram of patient allocation. DS, degenerative spondylolisthesis; MI, mid-range instability; TI, terminal-range instability.

Table 2. Radiographic data

\begin{tabular}{lc} 
Variable & Mean \pm standard deviation \\
\hline Average slip in N (mm) & $5.20 \pm 2.61$ \\
\hline Average slip in $\mathrm{M}(\mathrm{mm})$ & $6.57 \pm 2.76$ \\
\hline Average slip in T (mm) & $7.20 \pm 3.06$ \\
\hline Motion $\mathrm{M}-\mathrm{N}(\mathrm{mm})$ & $1.37 \pm 1.79$ \\
\hline Motion T-N (mm) & $2.00 \pm 2.30$ \\
\hline Motion T-M (mm) & $5.90 \pm 2.19$ \\
\hline Grade of stenosis & $2.13 \pm 0.94$ \\
\hline Lumbar lordosis $\left(^{\circ}\right)$ & $33.64 \pm 11.52$ \\
\hline
\end{tabular}

$\mathrm{N}$, extension; M, mid-range; T, end-range.

\section{Statistical analysis}

Comparison of each independent variable between the groups was done by independent $t$-test for continuous variables and $\chi^{2}$ test for categorical variable. Correlations were analyzed using Pearson's correlation test. All statistical analyses were performed using the SPSS ver. 17.0.0 statistics package (SPSS Inc., Chicago, IL, USA). A value of $p<0.05$ was accepted as significant.

\section{Results}

The average sagittal translation of the lumbar spine was $5.2 \mathrm{~mm}$ in extension, $6.6 \mathrm{~mm}$ in mid-range, and $7.2 \mathrm{~mm}$ in end-range (Table 2). MI was observed in eight patients (26.2\%) and TI was seen in 12 patients (40\%) (Fig. 1). Of eight patients with MI, three patients did not have instability at terminal-range (occult patients) (Fig. 2) and five patients had instability at terminal-range (typical patients) (Fig. 3). Body weight and body mass index (BMI) were significantly higher in the MI group as compared to the control group. BMI was positively correlated with slippage to mid-range (Table 3, Fig. 4). There was no significant
Table 3. Comparison between Ml group and control group

\begin{tabular}{lccr} 
Variable & $\begin{array}{c}\text { Ml group } \\
(\mathrm{n}=8)\end{array}$ & $\begin{array}{c}\text { Control group } \\
(\mathrm{n}=15)\end{array}$ & $p$-value \\
\hline Age $(\mathrm{yr})$ & $68.75 \pm 9.07$ & $67.20 \pm 8.69$ & 0.698 \\
\hline Body mass index $\left(\mathrm{kg} / \mathrm{m}^{2}\right)$ & $26.77 \pm 4.11$ & $23.85 \pm 2.44$ & 0.043 \\
\hline $\mathrm{M}-\mathrm{N}^{\mathrm{a})}(\mathrm{mm})$ & $3.88 \pm 2.47$ & $0.20 \pm 1.08$ & $<0.001$ \\
\hline Leg VAS & $5.38 \pm 2.62$ & $4.07 \pm 3.03$ & 0.315 \\
\hline Back VAS & $6.13 \pm 1.89$ & $6.20 \pm 2.51$ & 0.942 \\
\hline Oswestry Disability Index & $16.63 \pm 8.11$ & $25.00 \pm 10.08$ & 0.056 \\
\hline
\end{tabular}

Values are presented as number or mean \pm standard deviation. Bold type is considered statistically significant.

MI, mid-range instability; VAS, Visual Analog Scale.

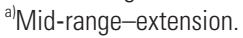

difference in stenosis grade, VAS, and ODI. In the TI group, there was no significant difference in radiographic or clinical parameters as compared to the control group (Table 4).

\section{Discussion}

The present study demonstrates that static clinical flexion-extension radiographs appear to underestimate the true degree of AP translation that occurs during trunk flexion when compared with dynamic in vivo continuous kinematic analysis in patients with DS. Dynamic imaging study of the lumbar spine has been attempted via digital fluoroscopic video of cineradiography with promising results, suggesting aberrant kinematics in the affected segments $[6,17,18]$. The aim of this study, then, is to provide a simple and practical method of assessment.

When analyzing the kinematic data presented, one can broadly categorize patients into three subgroups of DS: (1) "typical" motion, referring to the increase in anterior subluxation of the superior vertebral body on the inferior body as one's body flexes forward, (2) "paradoxical" mo- 

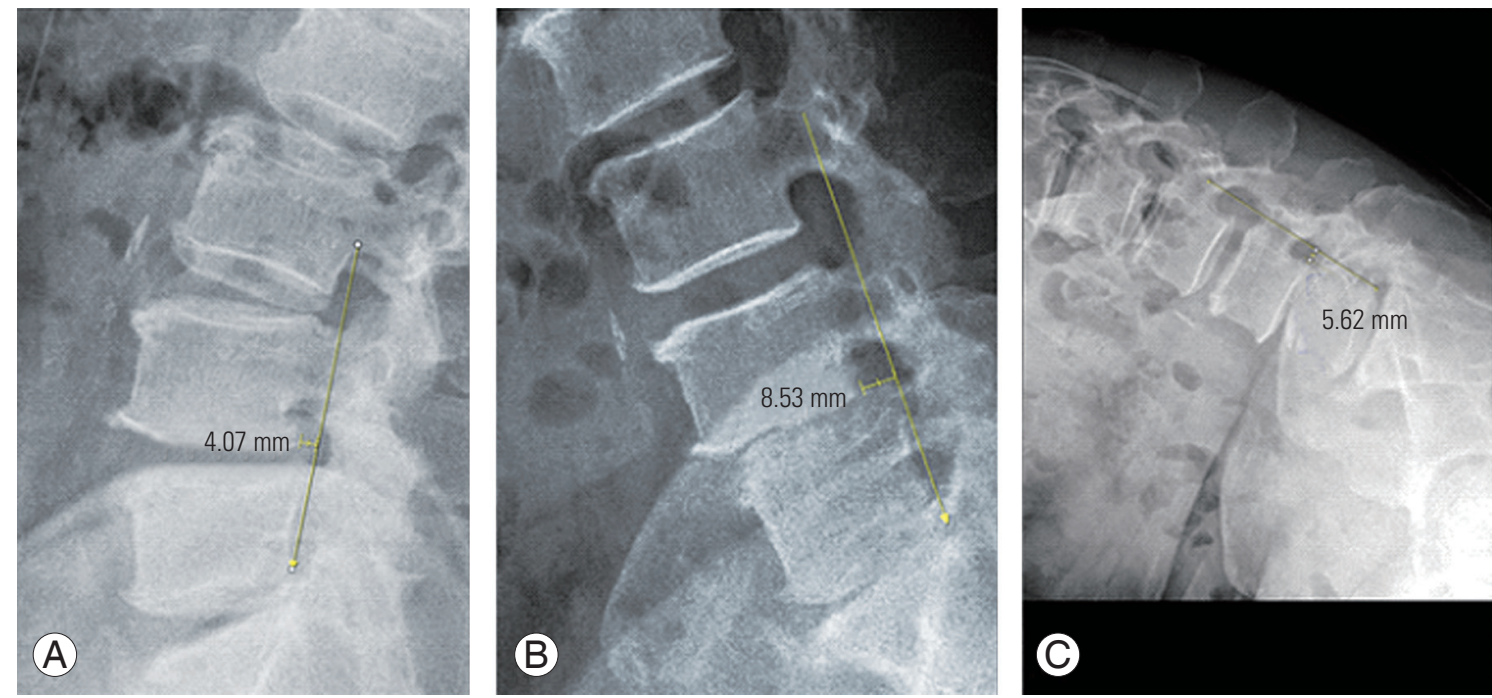

Fig. 2. Radiography of a 55-year-female with degenerative spondylolisthesis. (A) Upright extension lateral X-ray. (B) $45^{\circ}$ flexion (mid-range) lateral X-ray. (C) $90^{\circ}$ flexion (terminal-range) lateral X-ray. Slip length was (A) $4 \mathrm{~mm} \rightarrow$ (B) $8.5 \mathrm{~mm} \rightarrow$ (C) $5.6 \mathrm{~mm}$ occult instability with slip increase from mid-range to $8.5 \mathrm{~mm}$.
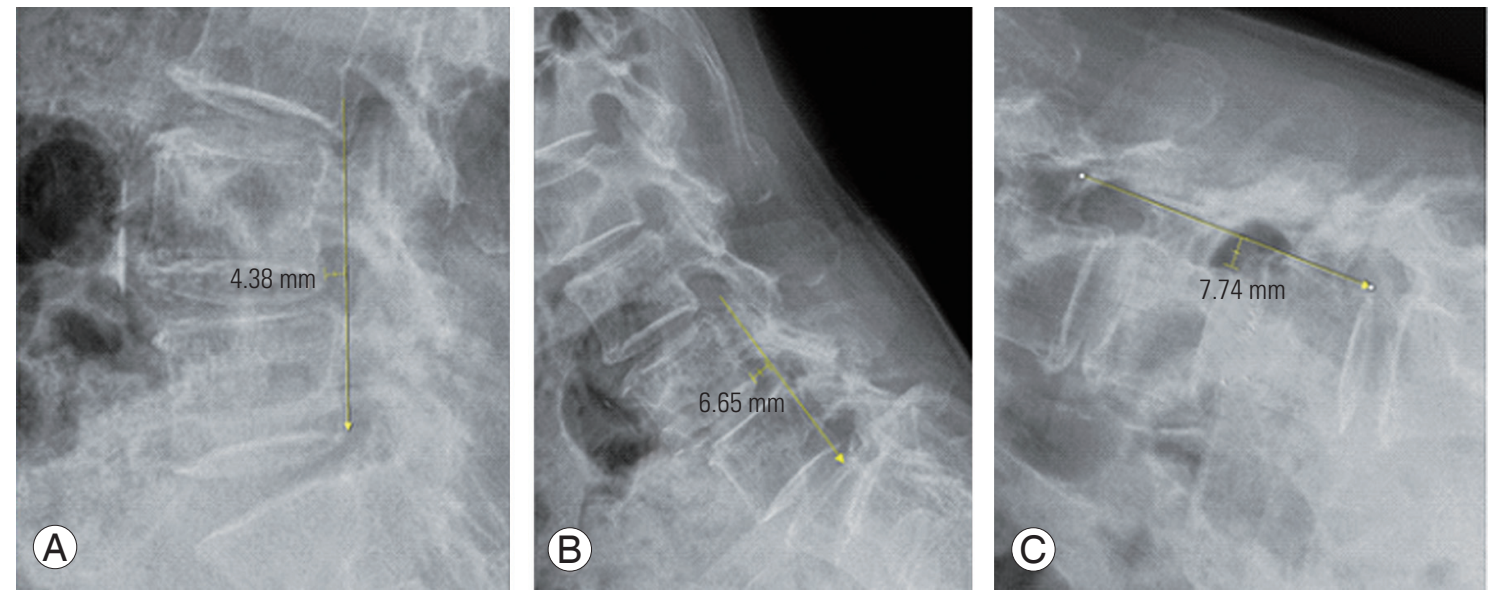

Fig. 3. Radiography of a 76-year-female with degenerative spondylolisthesis. (A) Upright extension lateral X-ray. (B) $45^{\circ}$ flexion (mid-range) lateral X-ray. (C) $90^{\circ}$ flexion (terminal-range) lateral X-ray. Slip length was (A) $4.4 \mathrm{~mm} \rightarrow$ (B) $6.7 \mathrm{~mm} \rightarrow$ (C) $7.7 \mathrm{~mm}$ typical instability with slip increase from terminal-range to $8 \mathrm{~mm}$.

Table 4. Comparison between TI group and control group

\begin{tabular}{lrrr} 
Variable & $\begin{array}{c}\text { Tl group } \\
(\mathrm{n}=12)\end{array}$ & $\begin{array}{c}\text { Control group } \\
(\mathrm{n}=15)\end{array}$ & $p$-value \\
\hline Age $(\mathrm{yr})$ & $70.08 \pm 7.85$ & $67.20 \pm 8.69$ & 0.380 \\
\hline Body mass index $\left(\mathrm{kg} / \mathrm{m}^{2}\right)$ & $24.44 \pm 2.99$ & $23.85 \pm 2.44$ & 0.576 \\
\hline${\left.\mathrm{T}-\mathrm{N}^{\mathrm{a}}\right)}^{(\mathrm{mm})}$ & $4.25 \pm 1.48$ & $0.33 \pm 1.35$ & $<0.001$ \\
\hline Leg VAS & $5.42 \pm 2.50$ & $4.07 \pm 3.03$ & 0.227 \\
\hline Back VAS & $5.67 \pm 2.06$ & $6.20 \pm 2.51$ & 0.559 \\
\hline Oswestry Disability Index & $24.42 \pm 8.03$ & $25.00 \pm 10.08$ & 0.872 \\
\hline
\end{tabular}

Values are presented as number or mean \pm standard deviation. Bold type is considered statistically significant.

$\mathrm{TI}$, terminal-range instability; VAS, Visual Analog Scale.

alEnd-range-extension. tion, referring to the decrease in anterior subluxation of the superior vertebral body as one's body flexes forward, and (3) "occult" motion, referring to sagittal translation of the superior vertebral body on the inferior vertebral body during mid-range flexion that reduces by the end-range of motion [19].

This data support that DS in fact represents a spectrum of aberrant motion with significantly greater kinematic heterogeneity than previously realized. Furthermore, our data suggest some patients exhibit so-called occult dynamic instability, i.e., AP translation not apparent using standard static clinical imaging, which may have 

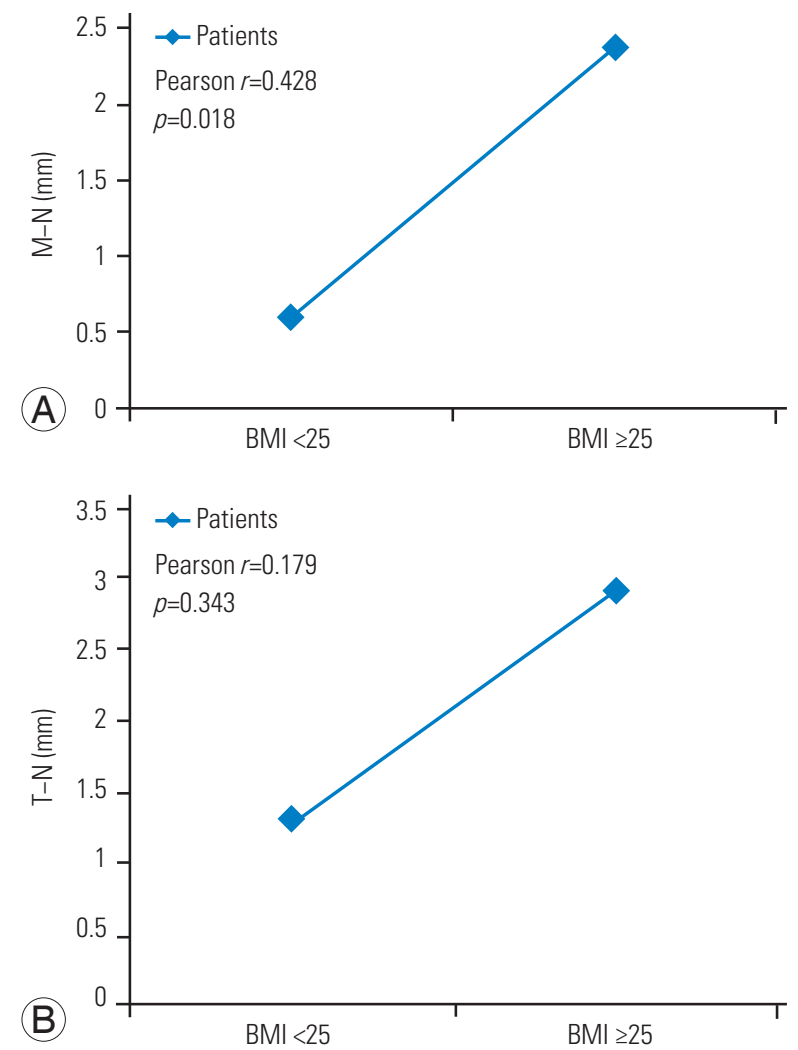

Fig. 4. (A, B) Correlation between slip and BMI. N, extension; M, mid-range; T, end-range; $\mathrm{BMI}$, body mass index $\left(\mathrm{kg} / \mathrm{m}^{2}\right)$.

important clinical implications for surgical management. Improving the detection of dynamic instability as well as furthering our understanding of different kinematic subgroups in DS could make possible more patient-specific rather than disease-specific surgical interventions. The present data suggest a subset of patients with "occult" dynamic instability, which can lead to a source of failure when treated via decompression surgery alone.

In Table 2, $\mathrm{T}$ (end-range)-N (extension) motion was $2.00 \pm 2.30 \mathrm{~mm}, \mathrm{~T}-\mathrm{M}$ (mid-range) was $5.90 \pm 2.19 \mathrm{~mm}$. Theoretically, T-N should be larger than T-M, but, T-M is larger because there is a corresponding number of patients reduced in the terminal.

There are some limitations to this study that deserve mention. First, our study consisted of a small sample size with only 30 patients. However, the sample size was large enough to identify distinct occult dynamic instability and the relationship between BMI and MI. Second, the lack of standardization of body flexion between patients may have impacted the observed kinematic patterns. In order to standardize the protocol, the subjects were asked to flex to their maximum amount without experiencing signifi- cant pain, similar to the clinical setting.

\section{Conclusions}

We suggest that some patients exhibit so-called occult dynamic instability, which has a relationship to BMI. This data not only improves the detection of dynamic instability, but also reduces surgical complications by not performing decompression surgery alone, especially with higher BMI patients.

\section{Conflict of Interest}

No potential conflict of interest relevant to this article was reported.

\section{ORCID}

Chang-Yk Lee: https://orcid.org/0000-0001-8780-1000

Byeong-Mun Park: https://orcid.org/0000-0003-2637-4257

Tae-Woo Kim: https://orcid.org/0000-0002-9419-412X

Seung-Hwan Lee: https://orcid.org/0000-0002-0432-3857

\section{References}

1. Resnick DK, Watters WC 3rd, Sharan A, et al. Guideline update for the performance of fusion procedures for degenerative disease of the lumbar spine: part 9: lumbar fusion for stenosis with spondylolisthesis. J Neurosurg Spine 2014;21:54-61.

2. Weinstein JN, Lurie JD, Tosteson TD, et al. Surgical compared with nonoperative treatment for lumbar degenerative spondylolisthesis: four-year results in the Spine Patient Outcomes Research Trial (SPORT) randomized and observational cohorts. J Bone Joint Surg Am 2009;91:1295-304.

3. Ghogawala Z, Dziura J, Butler WE, et al. Laminectomy plus fusion versus laminectomy alone for lumbar spondylolisthesis. N Engl J Med 2016;374:1424-34.

4. Herkowitz HN, Kurz LT. Degenerative lumbar spondylolisthesis with spinal stenosis: a prospective study comparing decompression with decompression and intertransverse process arthrodesis. J Bone Joint Surg Am 1991;73:802-8.

5. Blumenthal C, Curran J, Benzel EC, et al. Radiographic predictors of delayed instability following decompression without fusion for degenerative 
grade I lumbar spondylolisthesis. J Neurosurg Spine 2013;18:340-6.

6. Takayanagi K, Takahashi K, Yamagata M, Moriya $\mathrm{H}$, Kitahara $\mathrm{H}$, Tamaki T. Using cineradiography for continuous dynamic-motion analysis of the lumbar spine. Spine (Phila Pa 1976) 2001;26:1858-65.

7. Anderson DG, Limthongkul W, Sayadipour A, et al. A radiographic analysis of degenerative spondylolisthesis at the L4-5 level. J Neurosurg Spine 2012;16:130-4.

8. Quinnell RC, Stockdale HR. Flexion and extension radiography of the lumbar spine: a comparison with lumbar discography. Clin Radiol 1983;34:405-11.

9. Boden SD, Wiesel SW. Lumbosacral segmental motion in normal individuals: have we been measuring instability properly? Spine (Phila Pa 1976) 1990;15:571-6.

10. Hammouri QM, Haims AH, Simpson AK, Alqaqa A, Grauer JN. The utility of dynamic flexion-extension radiographs in the initial evaluation of the degenerative lumbar spine. Spine (Phila Pa 1976) 2007;32:2361-4.

11. Majid K, Fischgrund JS. Degenerative lumbar spondylolisthesis: trends in management. J Am Acad Orthop Surg 2008;16:208-15.

12. Bendo JA, Ong B. Importance of correlating static and dynamic imaging studies in diagnosing degenerative lumbar spondylolisthesis. Am J Orthop (Belle Mead NJ) 2001;30:247-50.
13. Wood KB, Popp CA, Transfeldt EE, Geissele AE. Radiographic evaluation of instability in spondylolisthesis. Spine (Phila Pa 1976) 1994;19:1697-703.

14. Phan KH, Daubs MD, Kupperman AI, Scott TP, Wang JC. Kinematic analysis of diseased and adjacent segments in degenerative lumbar spondylolisthesis. Spine J 2015;15:230-7.

15. Even JL, Chen AF, Lee JY. Imaging characteristics of "dynamic" versus "static" spondylolisthesis: analysis using magnetic resonance imaging and flexion/extension films. Spine J 2014;14:1965-9.

16. Matz PG, Meagher RJ, Lamer T, et al. Guideline summary review: an evidence-based clinical guideline for the diagnosis and treatment of degenerative lumbar spondylolisthesis. Spine J 2016;16:439-48.

17. Teyhen DS, Flynn TW, Childs JD, et al. Fluoroscopic video to identify aberrant lumbar motion. Spine (Phila Pa 1976) 2007;32:E220-9.

18. Otani K, Okawa A, Shinomiya K, Nakai O. Spondylolisthesis with postural slip reduction shows different motion patterns with video-fluoroscopic analysis. J Orthop Sci 2005;10:152-9.

19. Dombrowski ME, Rynearson B, LeVasseur C, et al. ISSLS Prize in Bioengineering Science 2018: dynamic imaging of degenerative spondylolisthesis reveals mid-range dynamic lumbar instability not evident on static clinical radiographs. Eur Spine J 2018;27:75262. 